\title{
Editorial
}

\section{Solar Energy and Clean Energy: Trends and Developments}

\author{
Ching-Song Jwo, ${ }^{1}$ Sih-Li Chen, ${ }^{2}$ Ho Chang, ${ }^{3}$ Yu-Shan Su, ${ }^{4}$ and Jen-Shiun Chen ${ }^{5}$ \\ ${ }^{1}$ Emission Reduction \& Energy Conservation Center, National Taipei University of Technology, 1, Section 3, Chung-Hsiao East Road, \\ Taipei 10608, Taiwan \\ ${ }^{2}$ Department of Mechanical Engineering, National Taiwan University, No. 1, Section 4, Roosevelt Road, Taipei 10617, Taiwan \\ ${ }^{3}$ Graduate Institute of Manufacturing Technology, National Taipei University of Technology, 1, Section 3, Chung-Hsiao East Road, \\ Taipei 10608, Taiwan \\ ${ }^{4}$ Department of Industrial Education, National Taiwan Normal University, No. 162, Section 1, Heping East Road, Taipei 106, Taiwan \\ ${ }^{5}$ Department of Electrical and Computer Engineering, Southern Illinois University Edwardsville, Campus Box 1801, \\ Edwardsville, IL 62026-180, USA
}

Correspondence should be addressed to Ching-Song Jwo; frankjwo@ntut.edu.tw

Received 18 April 2013; Accepted 18 April 2013

Copyright (C) 2013 Ching-Song Jwo et al. This is an open access article distributed under the Creative Commons Attribution License, which permits unrestricted use, distribution, and reproduction in any medium, provided the original work is properly cited.

Solar energy and other clean energies are emerging and growing rapidly in the globe nowadays. Solar energy with less carbon emission is renewable and clean energy for our living environment. Solar energy can be converted to electricity in photovoltaic (PV) devices, solar cells, or solar thermal/electric power plants.

It is a current trend that solar energy becomes the important renewable energy. This special issue addresses the role of the development of solar energy. The themes include fabrication methods, solar cell applications, theoretical analysis, and solar cell development trend. From 28 submissions, 19 papers are published in this special issue. Each paper was reviewed by at least two reviewers and revised according to review comments.

In Chu et al's paper, the authors presented the fabrication of large-grain $1.25 \mu \mathrm{m}$ thick polycrystalline silicon (poly-Si) films via two-stage aluminum-induced crystallization (AIC) for application in thin-film solar cells. In S. Chen et al's paper, the authors presented that the reactive sputtering is an effective technique of fabricating aluminum oxide surface passivation film for low-cost high efficiency crystalline silicon solar cells. In I.-J. No et al.'s paper, the authors presented the poly [[9-(1-Octylnonyl)-9H-carbazole-2,7Diyl]-2,5-thiophenediyl-2,1,3-benzothiadiazole-4,7-diyl-2,5thiophenediyl] $/[6,6]$-phenyl C71 butyric acid methyl ester blend active layers prepared by spray deposition method.
The photovoltaic cells were fabricated using the spray coated active layers with and without $\mathrm{TiO}_{x}$ layer. In L.-Y. Shi et al.'s paper, the authors presented that the dye-sensitized solar cells composed of the gel-type electrolyte with no ionic liquid added can acquire $4.13 \%$ photoelectric conversion efficiency. In C.-Y. Hsu et al.s paper, the authors presented that the precursor with a $\mathrm{Cu} /(\mathrm{In}+\mathrm{Ga})$ ratio of 0.95 exhibits larger grains and lower resistance, which is suitable for its application to solar cells. In C.-G. Kuo et al's paper, the authors presented that the measured photovoltaic performance of the dye-sensitized solar cells was dependent on the TNT-array length. In F.-H. Wang et al's paper, the authors presented that the efficiencies of the $\alpha$-Si thin-film solar cells increased from $2.83 \%$ to $3.38 \%$ as the deposition power decreased from $150 \mathrm{~W}$ to $50 \mathrm{~W}$ when the GZO thin films were used as the front transparent conductive thin films. In C.-G. Kuo et al.s paper, the authors presented that the electrochemical polishing-chemical etching and chemical etching processes were better for formation of $\mathrm{TiO}_{2}$ nanotube arrays than the polishing-chemical etching process because they could fabricate $\mathrm{TiO}_{2}$ nanotube arrays with the better characteristics to be used as the photoelectrodes of dye sensitized solar cells. In C.-R. Lin et al's paper, the authors presented depositing high transmittance diamond-like carbon (DLC) thin films on D263T glass substrate at room temperature via a diamond powder target using the radio 
frequency (RF) magnetron sputtering technique. DLC film under an RF power of $150 \mathrm{~W}$ possesses high transmissive ability $(>81 \%)$ and low average reflectance ability $(<9.5 \%)$ in the visible wavelengths (at $\lambda=400-700 \mathrm{~nm}$ ).

In A. Fudholi et al.'s paper, the authors presented the study evaluating the performance of solar drying in the Malaysian red chili (Capsicum annuum L.). Red chilies were dried down from approximately $80 \%(\mathrm{wb})$ to $10 \%(\mathrm{wb})$ moisture content within $33 \mathrm{~h}$. The drying process was conducted during the day, and it was compared with $65 \mathrm{~h}$ of open sun drying. Solar drying yielded a $49 \%$ saving in drying time compared with open sun drying. The progressive growing of single-phase photovoltaic (PV) systems makes the Distribution System Operators (DSO) update or revise the existing grid codes in order to guarantee the availability, quality, and reliability of the electrical system. It is expected that the future PV systems connected to the low-voltage grid will be more active with functionalities of low voltage ride-through (LVRT) and the grid support capability, which is not the case today. In Yang et al's paper, the authors presented a single-phase gridconnected PV system in low voltage ride through operation. The single-phase PV inverters connected to low-voltage networks are ready to provide grid support and ride-through voltage fault capability with satisfactory performance based on the grid requirements for three-phase renewable energy systems. In Z.-J. Chien et al.'s paper, the authors presented an absorption refrigerator driven by solar cells. The experiment shows the alternation of solar irradiance 550 to $700 \mathrm{w} / \mathrm{m}^{2}$ as solar energy source and $500 \mathrm{ml}$ ambient temperature water as cooling load. After 160 minutes, the proposal refrigerator can maintain the temperature at 5 to $8^{\circ} \mathrm{C}$, and the coefficient of performance (COP) of $\mathrm{NH}_{3}-\mathrm{H}_{2} \mathrm{O}$ absorption refrigeration system is about 0.25 . In C.-S. Jwo et al's paper, the authors presented wind directly forced heat pump. According to the experimental results, indicated average value for water producing efficiency was improved. In A. Kargarnejad et al.'s paper, the authors presented a new fuzzy-based controller to track the maximum power point of the solar panel also proposed which has better response from speed, accuracy, and stability points of view with respect to the previous common developed one.

In Daniela et al.s paper, the authors conducted experimentation and laboratory optical tests on solar components. It can analyze solar concentrators of various shapes, dimensions, and collection features. For Concentrating Photovoltaic systems, typically to characterise a solar component, the most important and commonly examined quantities are collection efficiency, image plane analysis, and angle dependence. In S. Zhang et al.'s paper, the authors presented that energetically most stable final charge transfer excited state is confirmed to be Por- $\mathrm{nT}^{\circ+}-\mathrm{C}^{\circ} 0^{\circ-}$ of PorphyrinOligothiophene-Fullerene Triads for the distance-dependent photoinduced electron transfer.

In Y.S. Su's paper, the author presented competing in the Taiwan solar photovoltaic industry trend.

These papers represent an exciting, insightful observation into the state of the art, as well as emerging future topics, in this important interdisciplinary field. We hope that this special issue would attract a major attention of the peers.

\section{Acknowledgment}

We would like to express our appreciation to all the authors and reviewers for great support to make this special issue possible.

Ching-Song Jwo
Sih-Li Chen
Ho Chang
Yu-Shan Su
Jen-Shiun Chen 

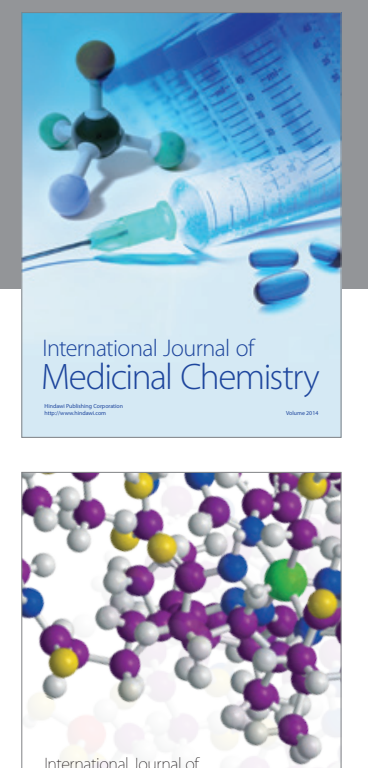

\section{Carbohydrate} Chemistry

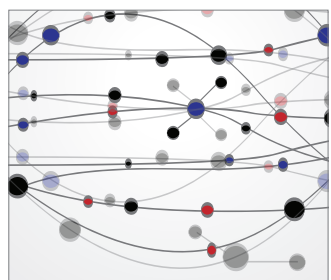

The Scientific World Journal
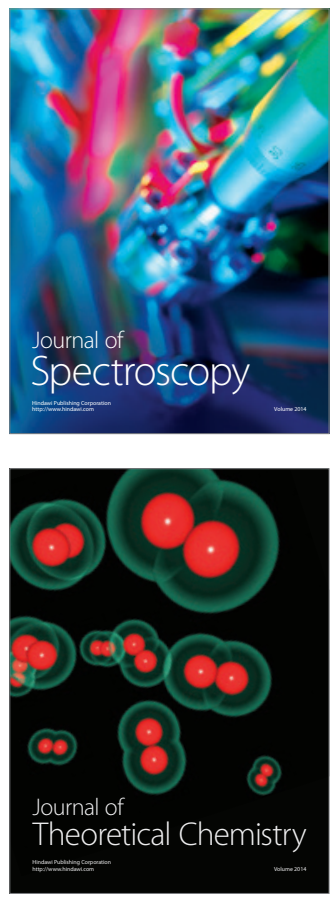
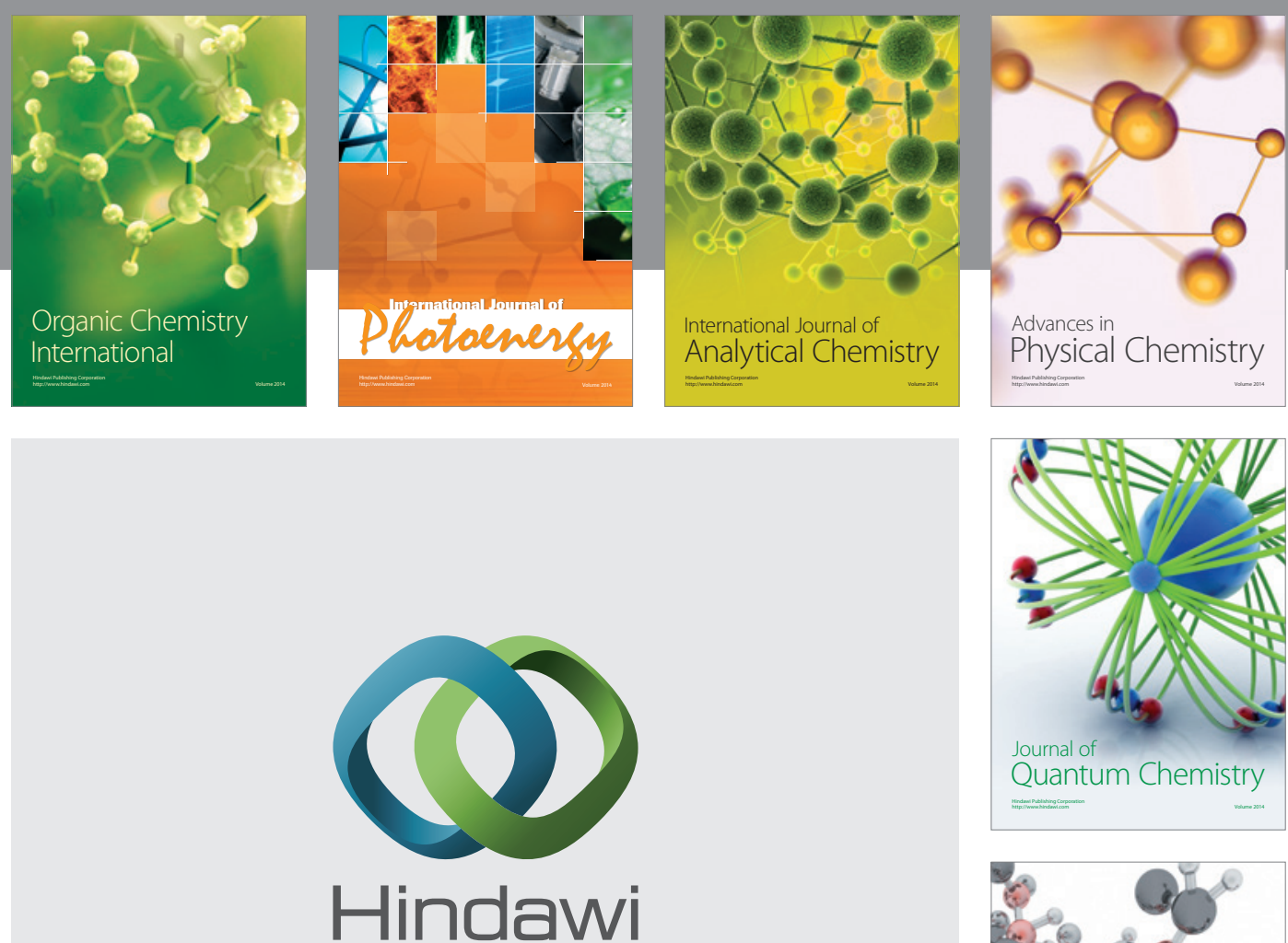

Submit your manuscripts at

http://www.hindawi.com

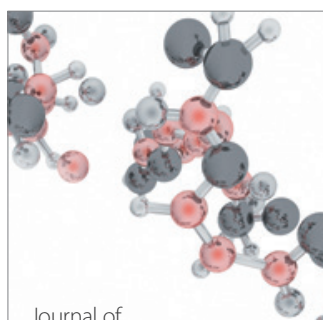

Analytical Methods

in Chemistry

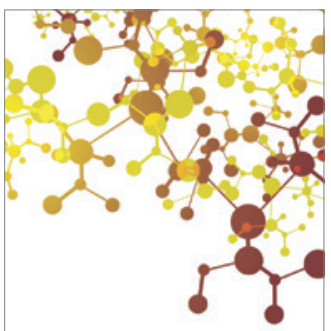

Journal of

Applied Chemistry

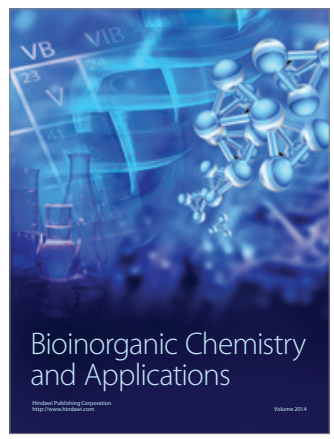

Inorganic Chemistry
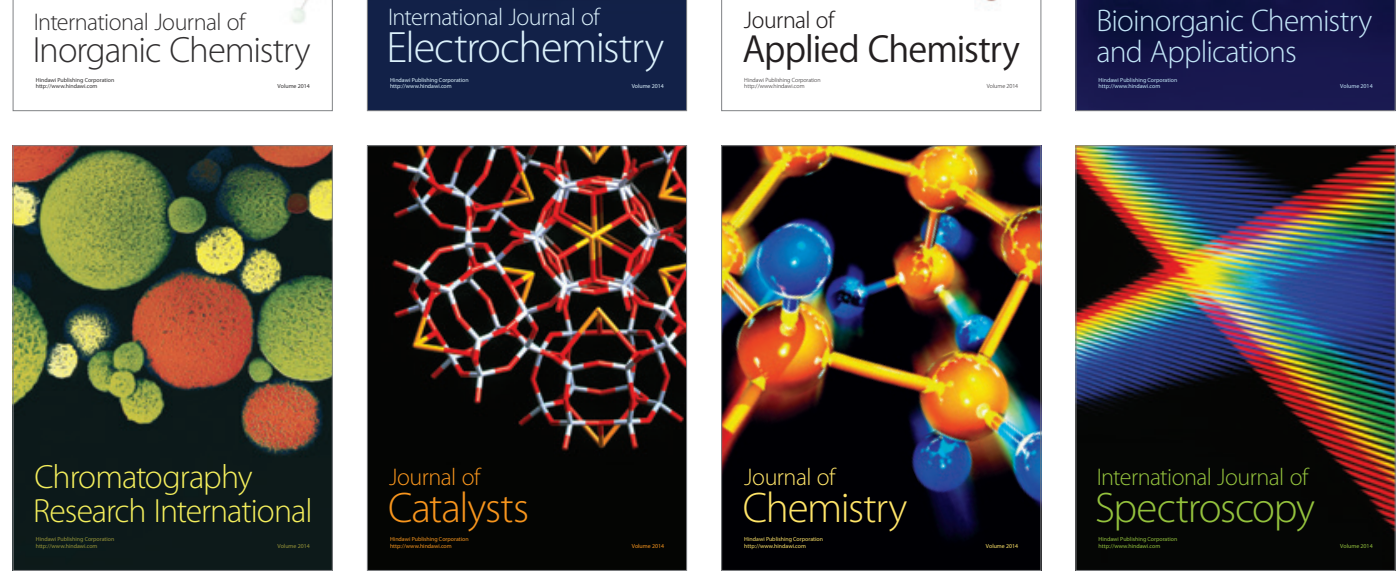